\title{
Evidence-Based Genetic Counseling for Psychiatric Disorders: A Road Map
}

\author{
Jehannine C. Austin ${ }^{1,2}$ \\ ${ }^{1}$ Departments of Psychiatry and Medical Genetics, University of British Columbia, Vancouver, British Columbia \\ V5Z 4H4, Canada \\ ${ }^{2}$ BC Mental Health and Substance Use Services Research Institute, Vancouver, British Columbia V6Z 2A9, \\ Canada \\ Correspondence: jehannine.austin@ubc.ca
}

Psychiatric disorders, such as schizophrenia, depression, anxiety, and bipolar disorder, are common conditions that arise as a result of complex and heterogeneous combinations of genetic and environmental factors. In contrast to childhood neurodevelopmental conditions such as autism and intellectual disability, there are no clinical practice guidelines for applying genetic testing in the context of these conditions. But genetic counseling and genetic testing are not synonymous, and people who live with psychiatric disorders and their family members are often interested in what psychiatric genetic counseling can offer. Further, research shows that it can improve outcomes like empowerment for this population. Despite this, psychiatric genetic counseling is not yet routinely or widely offered. This review describes the state of the evidence about the process and outcomes of psychiatric genetic counseling, focusing on its clinical implications and remaining research gaps.

$P^{s}$ ychiatric disorders, such as schizophrenia, bipolar, depression, and anxiety, are common conditions that have a complex and heterogeneous etiology and arise in individuals as a result of varied contributions of genetic and environmental factors (Schmitt et al. 2014; Psychiatric Genetics Consortium 2018). Psychiatric disorders are not entirely genetically determined, and genetic testing cannot establish, confirm, or refine a psychiatric diagnosis. Whereas genetic testing is considered a firsttier approach for childhood neurodevelopmental disorders (e.g., autism, intellectual disability) (Miller et al. 2010) to diagnose underlying genetic syndromes whose manifestations include

these phenotypes, genetic testing for psychiatric disorders is not standard clinical practice, nor is it suggested by any clinical practice guidelines in the context of psychiatric disorders like schizophrenia, bipolar, depression, anxiety, obsessivecompulsive disorder (OCD), eating disorders, etc. As an apparent consequence, genetic counseling is also not routinely provided for these conditions. However, benefits of genetic counseling do not depend on the use of genetic testing, and in most scenarios, neither necessitates the other.

Many clinical specialties within genetic counseling have emerged as a result of intuitive appreciation of patient needs in a particular area

Editors: Laura Hercher, Barbara Biesecker, and Jehannine C. Austin

Additional Perspectives on Genetic Counseling: Clinical Practice and Ethical Considerations available at www.perspectivesinmedicine.org

Copyright (C) 2020 Cold Spring Harbor Laboratory Press; all rights reserved; doi: 10.1101/cshperspect.a036608

Cite this article as Cold Spring Harb Perspect Med 2020;10:a036608 
J.C. Austin

and/or the availability of genetic tests. In contrast, the emergence of genetic counseling for psychiatric disorders is driven by evidence that shows a clinical need (Quaid et al. 2001; Meiser et al. 2005, 2008; Austin et al. 2006; DeLisi and Bertisch 2006; Lyus 2007; Wilhelm et al. 2009; Erickson et al. 2014; Quinn et al. 2014). Further, studies have found that even in the absence of genetic testing, psychiatric genetic counseling has benefits for people with psychiatric disorders and their families (Austin and Honer 2008; Hippman et al. 2013, 2016; Inglis et al. 2015; Moldovan et al. 2017). Herein, I review this literature, and present the psychiatric genetic counseling practice model established at the world's first specialist psychiatric genetic counseling clinic, which has been shown to produce positive patient outcomes.

\section{PSYCHIATRIC GENETIC COUNSELING: THE NEED}

Psychiatric genetic counseling for conditions such as schizophrenia, bipolar, eating disorders, depression, anxiety-like genetic counseling for any other conditions-seeks to help people make personal meaning of the factors that contribute to the development of the condition that they have or that runs in their family (Resta et al. 2006). Even without knowing the full range of issues that psychiatric genetic counseling can address, people with psychiatric disorders and their families are interested in what the service can offer (Quaid et al. 2001; Lyus 2007; Kalb et al. 2017). Commonly, people with psychiatric diagnoses and their family members overestimate chances for others in their family to develop similar conditions (and this influences childbearing decisions) (Austin et al. 2006); they feel guilty about personal choices they believe may have caused their illness, or feel powerless to do anything about their illness; and parents feel guilty about their children's psychiatric illnesses (either for passing on "bad" genes or perceived responsibility for suboptimal parenting or having failed to prevent their child's condition). Despite these cognitive and affective burdens, people with psychiatric disorders and their families are not routinely referred for ge- netic counseling (Hunter et al. 2009; Leach et al. 2016).

\section{THE HISTORY OF PSYCHIATRIC GENETIC COUNSELING RESEARCH}

Speculation in the research literature about the potential application and outcomes of psychiatric genetic counseling span several decades $(\mathrm{Ku}-$ mar 1968; Stancer and Wagener 1984; Reveley 1985; Hodgkinson et al. 2001; Austin and Honer 2004; DeLisi and Bertisch 2006; Finn and Smoller 2006; Lyus 2007; Bennett et al. 2008; Gershon and Alliey-Rodriguez 2013). Some of these writings reflect common misconceptions about psychiatric genetic counseling-for example, that it is primarily concerned with helping people to understand risk for recurrence in the family (Gershon and Alliey-Rodriguez 2013), or it could involve presenting psychiatric disorders as "genetic conditions" (Bennett et al. 2008). Although the moniker "genetic counseling" implies an exclusive focus on genetics, in the context of complex disorders like psychiatric conditions, genetic counseling should always include a holistic interactive discussion of both genetic and environmental factors that contribute to the condition, and, a skilled counselor is alert and prepared not only to address emergent thoughts but also emotional consequences of the exchange of information. The studies actually exploring the provision of psychiatric genetic counseling that have emerged subsequent to early speculation about its potential outcomes in the research literature have all embraced this model for delivery of the intervention. Specifically, the psychiatric genetic counseling outcomes research literature is based on a model of genetic counseling that involves discussion of the genetic and environmental contributors in a holistic manner. Practitioners approach psychiatric genetic counseling from the perspective of valuing the interaction as more existential than risk-specific and focusing on emotional issues that can arise during the discussion.

Results from an initial pilot study (Austin and Honer 2008), observational studies (Costain et al. 2012a,b), qualitative work (Hippman et al. 2013), and a randomized controlled trial (Hipp- 
man et al. 2016) of psychiatric genetic counseling provide collective evidence of positive outcomes for patients with psychiatric disorders and their family members. These data catalyzed the founding of the first specialist psychiatric genetic counseling clinic-the Adapt Clinic in Vancouver. A study assessing the outcomes of patients of the Adapt Clinic showed significant increases in measures of empowerment and selfefficacy after psychiatric genetic counseling with large effect sizes for empowerment (Inglis et al. 2015). Empowerment was assessed using the genetic counseling outcomes scale (GCOS) (McAllister et al. 2011). A subsequent qualitative study showed that for people with psychiatric diagnoses, psychiatric genetic counseling can help patients accept their illness at a deeper level and integrate it more fully into their sense of self in a manner that they experience as empowering (Semaka and Austin 2019).

Psychiatric genetic counseling is an emerging specialty within clinical genetics (Moldovan et al. 2019). Given the evidence for positive patient outcomes associated with psychiatric genetic counseling as practiced in the studies that formed the foundation for the Adapt Clinic, the structure and process of the clinic is described below. The clinic continues to collect patient outcome data and is exploring how patient- and session-related variables (e.g., specific psychiatric diagnosis, whether or not risk information is discussed) impact patient outcomes. In the following sections, when data are available regarding how patientand/or session-related variables impact patient outcomes, these are also discussed.

\section{STRUCTURAL OVERVIEW OF THE ADAPT CLINIC}

\section{The Team, the Referral Base}

The Adapt Clinic is a specialist psychiatric genetic counseling clinic. The name was developed in consultation with local psychiatrists who understood the value of the service and wished to, but were reluctant to, refer their patients for genetic counseling fearing their patients may interpret the referral as an indicator that their psychiatrist was implying that they should not have children.
The Adapt Clinic is housed within the existing general medical genetics clinic that services the province of British Columbia and uses two board-certified genetic counselors that are supported by a clinical secretary. A medical geneticist consults on cases in which a genetic syndrome is a possibility, based on medical/family history and signs off on clinical reports. A psychiatrist is available to consult on current mental health concerns (e.g., suicidality) that may be identified during a genetic counseling session. The clinic accepts referrals from both health-care providers (generally, psychiatrists who refer when patients ask specific questions about recurrence risks and/or etiology that they feel unequipped to address) (Leach et al. 2016) and self-referrals to ensure that barriers to access are as low as possible.

The clinic is available to men and women of any age who have a personal or family history of any psychiatric disorder. The service is covered by health insurance, and individuals are eligible for psychiatric genetic counseling if they reside within the geographical area served by the medical genetics center and have a personal and/or family history of a psychiatric disorder or genetic variation that confers increased risk for psychiatric illness.

\section{Preappointment Procedures}

On establishing initial contact, a phone call is booked to document family history in advance of the appointment. Initially, this protocol was established based on perceived advantages of this approach over that of documenting family history during the session. Subsequently, evidence has suggested advantages to this approach as greater increases in self-efficacy have been reported for patients whose family history was documented before their appointment than for those for whom it was documented in-session (Slomp et al. 2018). The phone call during which family history is documented takes, on average, about 45 minutes.

\section{Confirmation of Psychiatric Diagnoses}

Psychiatric diagnoses are established based on a clinical interview with a psychiatrist or other psychiatric health-care provider. There are no 
J.C. Austin

genetic tests with which to establish or confirm a psychiatric diagnosis. The Adapt Clinic counselors do not seek psychiatric records to confirm diagnoses for pragmatic reasons (e.g., challenges associated with obtaining consent to access records, psychiatric diagnoses can change over time). Rather, confidence in reported psychiatric diagnoses is established through the counselors' skills in eliciting information about psychiatric symptoms. Specifically, psychiatric interviewing skills are developed through a training that combines the use of the Structured Clinical Interview for Diagnostic Statistical Manual [DSM]) (First et al. 2015), the Positive and Negative Syndrome scale (Kay et al. 1987), and the Family Interview for Genetic studies (Maxwell 2018). The first two of these instruments focus on eliciting information about psychiatric symptomatology experienced by the interviewee, and the latter is an instrument used to assess psychiatric symptoms in a family member.

\section{Appointment and Follow-Up}

Psychiatric genetic counseling sessions (on average, 90 minutes in length) are provided inperson or by telephone or telehealth according to patient needs. Genetic testing is typically considered after consultation with the clinical geneticist when family/medial history is suggestive of a genetic syndrome that involves psychiatric manifestations as part of the phenotype (e.g., 22q11.2 deletion syndrome); outside of these relatively rare cases, no genetic testing is typically provided. After the session (described below), a consult report detailing the family history and issues discussed is sent to the referring healthcare provider, a physician of the patient's choosing, and/or the patient. A routine follow-up phone call (on average, $\sim 45$ minutes) is conducted approximately one month after the appointment to see if the patient wishes to return to discuss any additional issues - to date, $~ 5 \%$ of patients have returned for another appointment.

\section{Case Load, Supervision, Training}

In total, each patient requires four hours of counselor time (preappointment procedures, appointment, follow-up, charting, and letter writing). The clinic prioritizes ensuring that the counselor is able to provide quality care; therefore, participation in a one hour peer supervision session every two weeks is expected. To build capacity for the delivery of psychiatric genetic counseling, the clinic provides monthlong training rotations for about five genetic counseling students and two or three observers (typically health-care professionals from other countries) per year. Finally, to build relationships with the community to ensure awareness of our service, in addition to all these duties, the counselors engage in outreach and teaching.

\section{Evaluation of Patient Outcomes}

Three scales are used as clinical assessment tools: the GCOS (McAllister et al. 2011), the selfstigma in relatives of people with mental illness (SSRMI) scale (Morris et al. 2018), and the illness management self-efficacy scale (IMSES) (Lorig et al. 1996). Specifically, all are used during contracting at the beginning of the genetic counseling appointment (see Initial Contracting, below). The same instruments are also administered to structure the check in on psychological and emotional issues during the follow-up telephone call that is standard for all patients one month after their appointment. A clinical database containing this information, as well as demographic and referral information, is maintained by trained volunteers, supervised by the counselors. As these scales are administered both before and after genetic counseling, they can be used to assess change in outcomes for quality assurance/quality improvement processes, and, with appropriate ethical approvals to conduct retrospective chart reviews, they can then be used in addressing research questions about the impact of psychiatric genetic counseling on patient outcomes (e.g., Inglis et al. 2015; Morris et al. 2018; Slomp et al. 2018; Borle et al. 2018).

\section{PSYCHIATRIC GENETIC COUNSELING: CONTENT AND PROCESS}

The process and content of the psychiatric genetic counseling delivered in the Adapt Clinic is guided by and based on the research that pre- 
ceded the establishment of the clinic. The manual for psychiatric genetic counseling provided (see Table 1) summarizes the psychiatric genetic counseling as performed both in the context of the foundational research on which the Adapt Clinic is based and as provided in the Adapt Clinic. The manual is included as a quick refer- ence guide for others who may want to ensure that the process and content of their psychiatric genetic counseling is evidence based. Specific suggestions for how to raise some of the most important issues and key messages to explicitly state for patients are listed elsewhere (see Inglis et al. 2017).

Table 1. Psychiatric genetic counseling manual

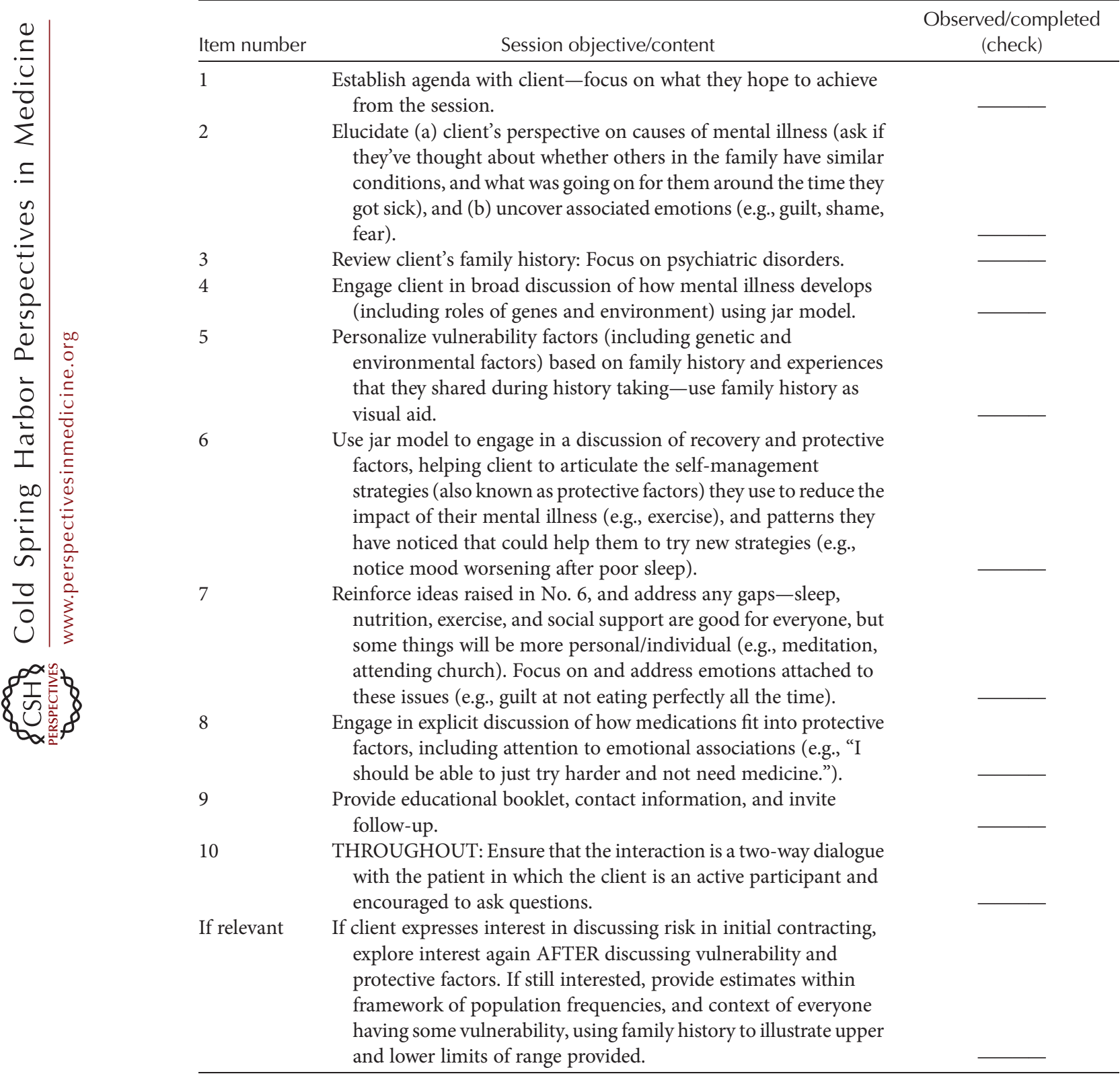


J.C. Austin

\section{Initial Contracting}

As in all genetic counseling, contracting around the reasons/motivations for the visit at a level beyond the superficial is crucial. For example, a person attending the appointment may articulate that they are there because they want to know what the chances are for their child to develop psychiatric illness, based on the family history. However, in this case, it may be deep fear, anticipatory guilt, and/or a need for control that is motivating the need to discuss risk. The most effective counseling is achieved when these underlying factors are uncovered and addressed.

The use of scales with patients during contracting allows them to communicate their needs or identify areas in which they are experiencing distress. This practice can be helpful in preparing genetic counselors to attend more specifically to these deeper layers or emotional aspects of the session, which has been shown to lead to enhanced patient outcomes (Eijzenga et al. 2014). The GCOS is used with all patients, the IMSES is used to assess confidence to manage illness with those who live with a psychiatric diagnosis, and the SSRMI scale is used to assess internalized stigma among those with no diagnosis themselves (i.e., people who have a relative with psychiatric illness). All can be useful in establishing key issues affecting participants' lives, which are likely to need to be addressed in the genetic counseling session. For example, if a patient strongly agrees with the GCOS item concerning guilt about passing on a condition, the counselor will propose that as a topic for discussion.

In the most recent assessment, the most commonly reported indication for attending the clinic ( $62 \%$ of attendees) was "to understand the causes of mental illness" (Borle et al. 2018). In practice, this is characterized by existential or affective, rather than cognitive or theoretical questions. Common questions are "Why me?" and "Is there anything I can do to prevent an (other) episode of mental illness?" The second most common reported reason for attending (44\% of attendees) was "to learn chance of illness recurrence" (Borle et al. 2018).

When a patient expresses during contracting that their primary-or only-motivation for attending genetic counseling is to discuss the chance for others in the family to develop psychiatric illness, or to understand options for genetic testing, the counselors do not immediately address either specific issue. Instead, they use the contracting process to seek to understand the deeper, emotional motivation for the patient to be seeking that information. The counselor also explains that people usually find it provides helpful context to discuss the factors that contribute both to development of illness, and to recovery first, before discussing risk and/or testing. Thus, the contracting process helps to ensure that patients' articulated needs are met as a result of probing by the counselor that facilitates insight into deeper related issues of concern. Setting expectations for a session that addresses these issues expands the likelihood of a broader benefit from the session.

\section{Psychotherapeutically Oriented Information Exchange \\ Etiology}

The need to establish a clear understanding of the patient's explanation of cause of the personal or familial condition is foundational for any genetic counseling encounter. The psychiatric family history can be used to reflect on perceptions of causation, and discussion of life experiences around or preceding symptom onset can be especially useful for the counselor to understand. Once a clear picture of the patients' perceptions of cause have been established, the counselor can introduce the jar model as a visual representation of the way that genetic and environmental (or experiential) vulnerability factors contribute together to the onset of psychiatric illness (see Fig. 1).

The Adapt Clinic experience has found that presenting the model first in terms of broad overall concepts, and personalizing by integrating it with concepts from the patient's initial reflections (e.g., showing how certain specific stressful life events they mentioned could have contributed environmental vulnerability into the jar, or how family history of related psychiatric disorders can translate to increased genetic vulnerability), is an effective approach. 

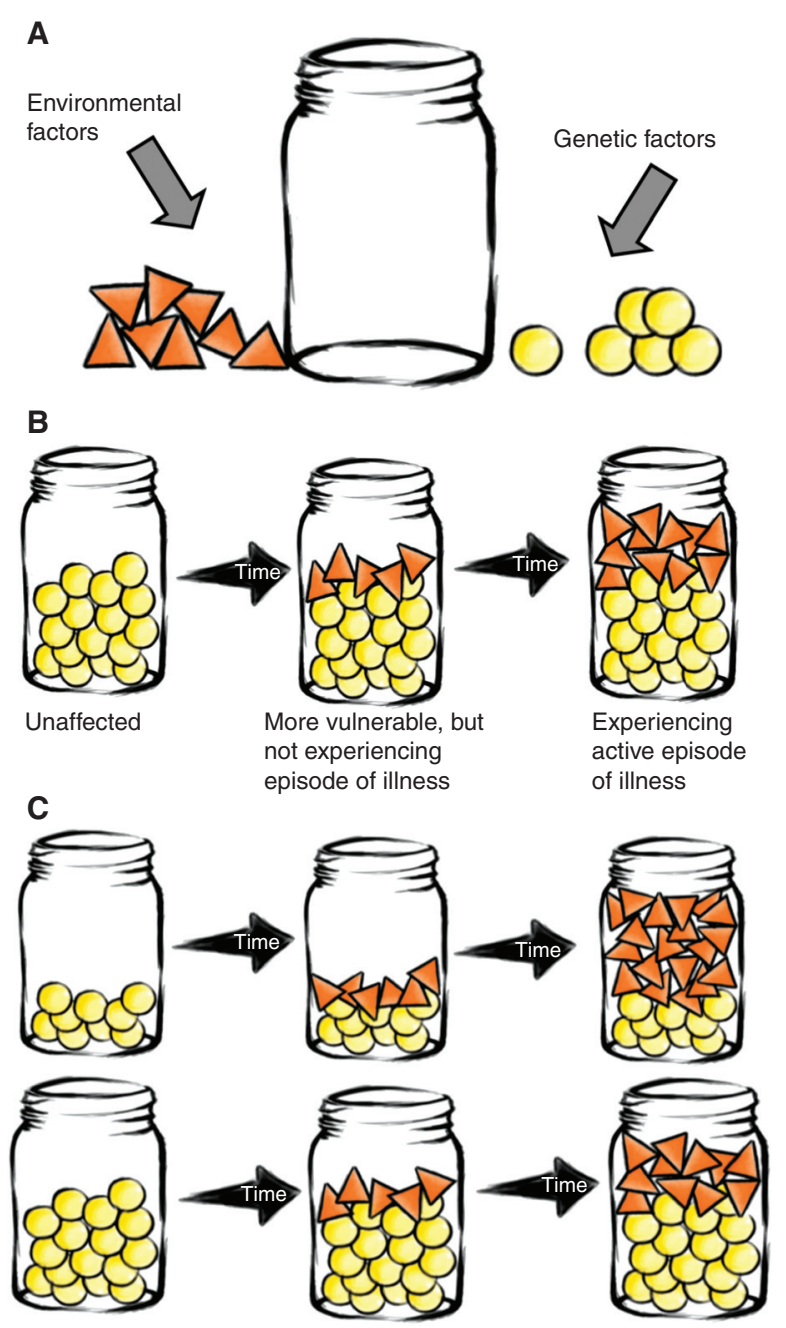

Figure 1. Introducing the concept of the jar model. (A) Everyone has a mental illness jar; it can be filled with two kinds of vulnerability factors. $(B)$ The amount of genetic vulnerability in the jar does not change over time, unlike experiential vulnerability. To experience an active episode of illness, the jar must be full to the top. (C) Someone with a large amount of genetic vulnerability may be more likely to develop mental illness than someone with a small amount-it is more likely that the jar will fill all the way. Someone with a large amount of genetic vulnerability may develop mental illness at a younger age than someone with a small amount-it takes less time for the jar to fill up. (Figures reprinted, with permission, from Peay and Austin 2011.)

Although there are, theoretically, many possible ways of visually representing how genes and environment contribute together to the development of complex disorders, evidence supports the effectiveness of the jar model in conveying complex inheritance among psychiatric genetic counseling clients (Hippman et al. 2016; Semaka and Austin 2019).
Throughout the discussion about etiology, the counselor attends to the patient's responses and is ready, for example, to clarify how a lack of a family history of psychiatric illness does not imply the patient has no genetic vulnerability-research clearly shows that everyone has some genetic vulnerability to psychiatric disorders (see Fig. 2); and address issues, such as 

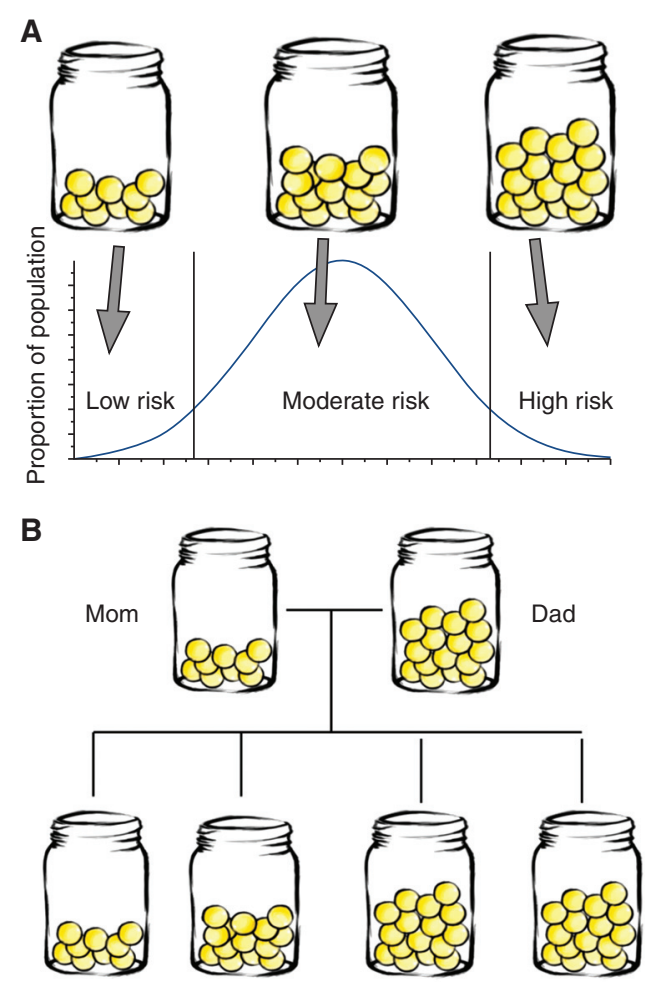

Figure 2. Everyone has some genetic vulnerability to mental illness. (A) Genome-wide association studies show that we all have some genetic vulnerability to mental illness-the variations are so common. We will vary in how much genetic vulnerability we each have with most people having a moderate amount. (B) Having no one in the family with a history of psychiatric illness does not preclude having inherited genetic vulnerability to mental illness; it simply means that other family members' jars did not fill to the top. (Figures reprinted, with permission, from Peay and Austin 2011.)

guilt, around how a history of substance use may have contributed to vulnerability, oramong parents-around how passing on "bad genes" may have contributed. The counselor's objectives are, first, to ensure that the patient understands that psychiatric illness is not their fault and is in no way a moral failing. The second objective is to establish a model of genes and environment that has direct personal relevance to the patient to provide a framework for discussing how to protect their future mental health.

\section{Recovery}

One of the components of psychiatric genetic counseling that patients find most impactful (Semaka and Austin 2019) is using the model for cause of illness as a framework for discussing how people can reduce risk for illness onset and/or recover from active episodes of illness. Again, the Adapt Clinic experience suggests that an effective approach to this involves first introducing the broad concept of factors that are protective to mental health (using the jar mod$\mathrm{el}$ ), and then opening a two-way discussion, drawing on the patient's experience, when possible, about how some protective factors (sleep, nutrition, exercise, good social support, and finding effective ways to manage stress) are useful. The counselors find it effective to emphasize that these are examples of protective factors for mental health that can be applied to everyone, regardless of whether or not we have ever had a diagnosis of a psychiatric disorder (see Fig. 3), whereas other strategies (i.e., use of psychotropic medication) can be useful for those who have had a diagnosis, and yet other strategies (e.g., avoiding street drugs like crystal meth and cannabis) can be particularly important for those who may have elevated risk for conditions that involve psychosis.

In addition to discussing protective strategies broadly, the counselor spends time working with the patient to identify specific protective factors that they identify as important for them. Although having good social support and finding effective ways to manage stress are strategies that can be helpful for everyone, the specific ways in which people achieve this vary. Helping a patient to identify the specific activities that work for them (e.g., attending church, spending time with a pet, journaling, cooking) can be helpful. Through this discussion, the counselor is vigilant in attending to signs of emotional response (e.g., "I should just be able to try harder to get better," "I shouldn't need medicine," "it's my fault I developed [condition $\mathrm{x}$ ] because I used too much cannabis when I was young"), which he or she then explicitly identifies and addresses (e.g., "It sounds like you feel it's your fault that you have mental illness-it's not. Many people 
A

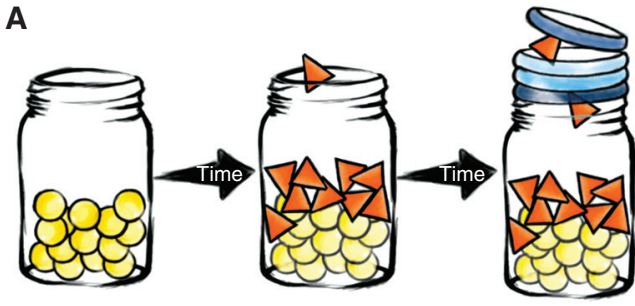

B

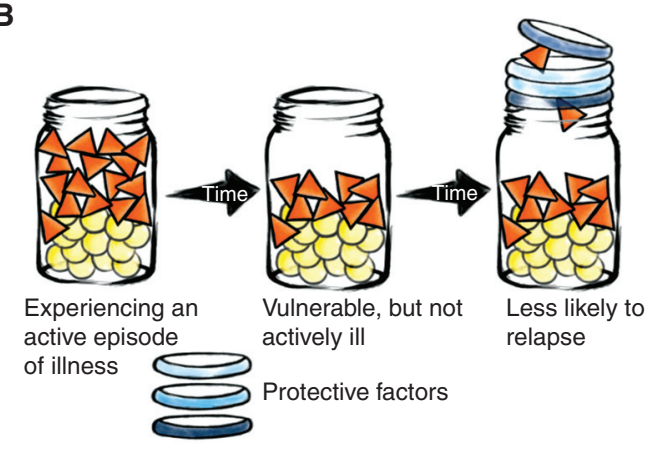

Figure 3. Recovery and reducing risk. (A) Reducing risk: Protective factors stack on top of the jar, making it taller and therefore able to accommodate more environmental factors before becoming full. Some protective factors are good for all of us (e.g., sleep, nutrition, exercise, social support, finding effective ways for managing stress), but some may be more unique to us. (B) Recovery from an active episode of illness: Sometimes, it may be possible to remove some of our environmental vulnerability factors (e.g., removing oneself from a particularly stressful situation, stopping use of crystal meth). But even if there are no modifiable vulnerability factors, protective factors can help increase the capacity of the jar-in addition to those noted above, medication can also be useful for those who have been diagnosed with mental illness. (Figures reprinted, with permission, from Peay and Austin 2011.)

use cannabis without getting sick, and cannabis on its own is not enough to cause [condition $\mathrm{x}$ ]"). The counselor communicates with the patient about how use of protective factors cannot definitively prevent an episode of mental illness, that perfection in performing all of these selfcare strategies is impossible, and the goal is not to strive for that, but to do what you can, and celebrate that with self-compassion.

Framing the discussion about strategies for recovery in terms of understanding the cause of illness can be powerful; people intuitively want their treatment for illness to reflect what they perceive to be the cause. Clinic patients regularly experience shifts in attitude toward psychotropic medication use through genetic counseling; understanding that there is a genetic (biological) contribution helps some individuals to see how a biological treatment could be helpful, whereas for others, understanding it is not all biological motivates people to engage in self-care strategies to protect their mental health. In the context of psychiatric genetic counseling, a key part of facilitating meaning-making and adaptation is helping patients to apply their new or deeper understanding of cause of illness to come up with strategies to protect their mental health for the future.

\section{Discussing Chance for Familial Recurrence}

As described in Initial Contracting, data show that $<50 \%$ of individuals presenting for psychiatric genetic counseling are interested in discussing chance for familial recurrence at the time of referral/initial contracting. Any discussion about risk is framed in the context of shared understanding of illness etiology, so after discussing psychiatric disorder etiology and recovery (as presented above) the counselor checks in to see if the patient would like to discuss specific numbers-essentially, this is a second contracting step that is specifically concerned with discussing chances for familial recurrence. Some patients $(>25 \%)$ who indicate at initial contracting that they want to discuss chances for familial recurrence change their mind after discussing etiology, as do $11 \%$ of those who initially indicate not wanting to discuss chances for familial recurrence (Borle et al. 2018). Ultimately, after the discussions described above regarding etiology and recovery, $\sim 40 \%$ of clinic patients opt to discuss specific chances for familial recurrence. Whereas all patients (even those who learn that the chances for familial recurrence are higher than they expected) benefit from psychiatric genetic counseling, those with the largest increases in empowerment were people who initially indicated wanting to know chances for familial recurrence, but changed their minds after dis- 
J.C. Austin

cussing etiology/recovery (Borle et al. 2018). This suggests that addressing the underlying (emotional) motivation for interest in risk information, as discussed above, is sufficiently powerful.

The second contracting step focuses on chances for familial recurrence and ensures that the process of psychiatric genetic counseling is as patient-centered as possible. When specific chances are discussed, they are provided only for the patient and/or children under the patient's guardianship (i.e., specific chances for a child to develop a psychiatric disorder would not be provided to grandparents if they are not guardians of the child in question). Specific chances are based on analysis of a detailed, three-generation psychiatric family history using empiric data (Austin et al. 2008), provided in the form of absolute risks and frequencies with broad ranges, and always discussed in the context of population rates. As with all other components of psychiatric genetic counseling, throughout the discussion of chances for familial recurrence, the counselor works to understand and address affective responses.

\section{Closing the Session}

To close the session, the counselor ensures that the patient is aware of plans to connect by phone one month later, confirms the health-care professionals to whom consult reports should be sent, and provides resources, including referrals to other professionals or community supports, and written material to take home (an educational booklet that is available for download in several languages from the National Society of Genetic Counselors [NSGC], Canadian Association of Genetic Counselors [CAGC], and Association of Genetic Nurses and Counsellors [AGNC]websites).

Impact of Symptoms of Indicated Condition on the Appointment

In most genetic counseling specialties, patients showing symptoms of the condition for which they were referred will not directly impact the counseling interaction. This maxim holds true for the vast majority of psychiatric genetic counseling sessions as well. But one of the most common questions received by Adapt Clinic counselors from other counselors about psychiatric genetic counseling concerns the potential for symptoms of psychiatric illness to impact the counseling interaction and thereby confound our ability to meaningfully help patients-for example, what if a patient does not have insight into the fact that they have a psychiatric diagnosis? How do you counsel a patient who is experiencing psychosis? Is a patient with a psychiatric disorder too fragile to discuss the issues that constitute the focus of a genetic counseling interaction-will it trigger an illness episode?

Inherently, those who physically attend a psychiatric genetic counseling appointment are organized and functioning well enough to get there at the scheduled time. Attending an appointment after the initial phone call during which family history and the broad purpose of the session are discussed implies that the individual is ready to discuss psychiatric disorders in the context of their family, and, if they have been referred for personal history of psychiatric illness, it implies that they self-identify as having at least some component of a psychiatric diagnosis. Importantly, people can be meaningfully helped in genetic counseling even if they do not identity with the specific label they have received -for example, for someone who identifies as having experienced mania but rejects the label of bipolar disorder, the genetic counseling session can simply focus on factors that contribute to or reduce the chance for an episode of mania. Although patients can be counseled-and with positive outcomes-when experiencing active episodes of illness, it is always an option to ask a patient if they feel that rescheduling for another time may allow them to benefit maximally from the interaction. When concerned about suicidality, it is important to check in on this explicitly-many tools and checklists exist to help with this and identify critical next steps. Contrary to popular concern, asking about suicidal ideation does not trigger suicidal reactions; in fact, research shows it has the opposite effect (Dazzi et al. 2014). It is crucial to remember that people who live with psychiatric illness are often 
deeply resilient, and the interactions that we can offer in genetic counseling, when applied as described above, can lead to meaningful positive outcomes for individuals who are often underserved.

\section{OUTCOMES OF PSYCHIATRIC GENETIC COUNSELING}

In qualitative work, recipients of psychiatric genetic counseling report that they perceive the process described in this review as allowing them to feel heard, validated, and supported ("It was like] talking to someone intelligent and understanding and knowledgeable, who listened and [was] genuinely interested, you could tell she cared about the subject and helping people, helping me") (Semaka and Austin 2019). The outcome of psychiatric genetic counseling, when using tools like the jar model as described above, was articulated beautifully by one interviewee: "[Psychiatric genetic counseling] made me feel more empowered in the things that I can do, like it made me more empowered to be able to manage what I've been given or where I'm at now. Whatever has happened, whatever I've done or not done that has caused my jar to look
Genetic Counseling for Psychiatric Disorders

the way it does, whether I've added the little triangles or not, I still have the power to add rings and to ensure that I'm protecting myself' (Semaka and Austin 2019).

Quantitative research shows that psychiatric genetic counseling can increase knowledge (Hippman et al. 2016), improve accuracy of risk perception (Hippman et al. 2016), and increase both empowerment and self-efficacy (Inglis et al. 2015). At least for empowerment, these effects seem to be sustained over time (see Fig. 4).

Empowerment and self-efficacy are important outcomes for two reasons. First, they are important for their own sake; in qualitative work, people talked about how the process of empowerment through psychiatric genetic counseling facilitated a deeper and fuller integration of their acceptance of their mental illness into their sense of self (Semaka and Austin 2019). Second-and crucially-empowerment and self-efficacy are necessary (although not sufficient) for people to engage in behavioral change that can help to protect their mental health. Indeed, in qualitative work, some people with mental illness who had received genetic counseling talked about how the process had

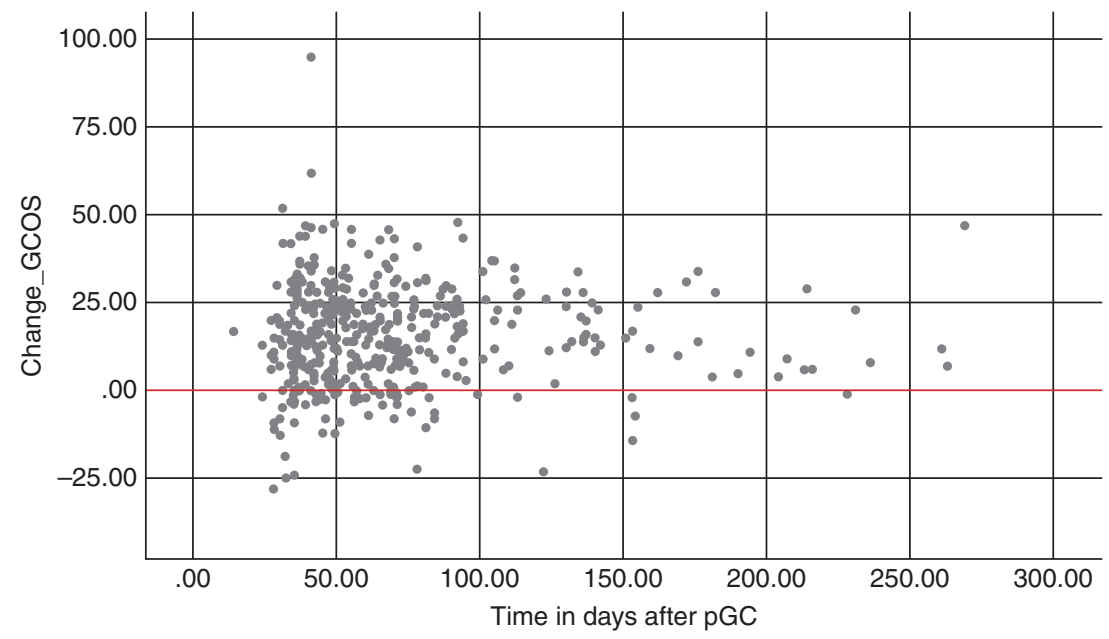

Figure 4. Empowerment scores on the genetic counseling outcomes scale (GCOS) over time after genetic counseling. Change in GCOS scores from pre- to postpsychiatric genetic counseling, shown according to length of time (in days) between pre- and postgenetic counseling data collection, showing that outcomes of psychiatric genetic counseling seem to be stable over at least 6 months postintervention. (pGC) Postgenetic counseling. (Figure provided by Emily Morris.) 
J.C. Austin

empowered them to "adopt new protective strategies like good sleep, nutrition, and exercise” (Semaka and Austin 2019).

\section{THE FUTURE}

Continuing to Explore Outcomes of Psychiatric Genetic Counseling

The evidence from quantitative work showing increased empowerment and self-efficacy after psychiatric genetic counseling, and the subsequent suggestion from qualitative work that people engage in behavior changes to better protect their mental health after receiving psychiatric genetic counseling, raises the question of whether psychiatric genetic counseling can ultimately influence mental health outcomes. Ongoing work within the Translational Psychiatric Genetics Group in Vancouver is exploring the effect of psychiatric genetic counseling on behavior change, medication adherence among people with psychiatric disorders, and mental health outcomes (like frequency and duration of mental health hospitalizations). As well, we are currently exploring how variables such as specific psychiatric diagnosis, time since diagnosis, and method of service delivery may influence outcomes of psychiatric genetic counseling for those who have a psychiatric diagnosis. Among relatives of those with psychiatric diagnoses, we are examining whether genetic counseling influences internalized stigma.

\section{Genetic Testing}

Conversations continue in the psychiatric genetics community regarding whether genetic testing for copy number variations (CNVs) should routinely be offered for subgroups of patients (https://ispg.net/genetic-testing-statement/) - for example, those with schizophrenia. As well, the availability of polygenic risk scores indicating risk for complex conditions, including psychiatric disorders, has pushed this type of testing to the forefront-pressing us to consider if and how to apply or manage them in clinical settings. It is critical to remain aware that the application of any type of genetic test in the context of psy- chiatric genetic counseling will not represent a fundamental paradigm shift; these tests cannot diagnose a psychiatric disorder or definitively determine whether or not someone will develop one. Any testing applied in a psychiatric genetic counseling context will be, at best, probabilistic information about risk and must still be applied in the context of an encounter that addresses the emotional issues - guilt, blame, shame, fear, and stigma-that are so often attached to people's explanations for cause of illness. As technology evolves, we serve our patients best by remembering that the most important and impactful work of the genetic counselor is achieved by using these tools in the context of an encounter that is psychotherapeutically focused (Austin et al. 2014).

\section{CONCLUDING REMARKS}

In sum, qualitative and quantitative work point to important outcomes of psychiatric genetic counseling for those who live with psychiatric conditions and their families. These outcomes are a result of genetic counselors' use of the tools and strategies described here to successfully walk the fine line of helping people understand that mental illness is not their fault, but there are things that they can do to protect their mental health going forward. Given the important outcomes that genetic counseling can produce in the context of adult psychiatric disorders (even in the absence of genetic testing), it is crucial that clinical genetics services prioritize this population-who have historically been so underserved by our area of medicine-for receipt of services.

Further, the model outlined here for the evaluation of outcomes of clinical services (i.e., integration of psychometric instruments as clinical assessment tools) and exploration of a logically progressive sequence of outcomes could be more broadly applied in other genetic counseling settings.

\section{ACKNOWLEDGMENTS}

I offer sincere thanks to past and present members of the Translational Psychiatric Genetics 
Group in Vancouver for their varied support, commitment, and contributions. Without all of you-past and present-the work on which this manuscript is founded would not have been possible. In particular, for this manuscript, I offer the deepest gratitude to Emily Morris, who contributed Figure 4. Finally, I was supported by the Canada Research Chairs Program and BC Mental Health and Substance Use Services.

\section{REFERENCES}

Austin JC, Honer WG. 2005. The potential impact of genetic counseling for mental illness. Clin Genet 67: 134-142.

Austin JC, Honer WG. 2008. Psychiatric genetic counselling for parents of individuals affected with psychotic disorders: a pilot study. Early Int Psychiatry 2: 80-89. doi:10 $.1111 / \mathrm{j} .1751-7893.2008 .00062 . \mathrm{x}$

Austin JC, Smith GN, Honer WG. 2006. The genomic era and perceptions of psychotic disorders: genetic risk estimation, associations with reproductive decisions and views about predictive testing. Am J Med Genet B Neuropsychiatr Genet 141B: 926-928. doi:10.1002/ajmg.b .30372

Austin JC, Palmer CGS, Rosen-Sheidley B, Veach PM, Gettig E, Peay HL. 2008. Psychiatric disorders in clinical genetics II: individualizing recurrence risks. J Genet Couns 17: 1829. doi:10.1007/s10897-007-9121-4

Austin J, Semaka A, Hadjipavlou G. 2014. Conceptualizing genetic counseling as psychotherapy in the era of genomic medicine. J Genet Couns 23: 903-909. doi:10.1007/ s10897-014-9728-1

Bennett L, Thirlaway K, Murray AJ. 2008. The stigmatising implications of presenting schizophrenia as a genetic disease. J Genet Couns 17: 550-559. doi:10.1007/s10897008-9178-8

Bipolar Disorder and Schizophrenia Working Group of the Psychiatric Genomics Consortium, Ruderfer DM, Ripke S, McQuillin A, Boocock J, Stahl EA, Whitehead Pavlides JM, Mullins N, Charney AW, Ori APS, et al. 2018. Genomic dissection of bipolar disorder and schizophrenia, including 28 sub-phenotypes. Cell 173: 1705-1715.e16. doi:10.1016/j.cell.2018.05.046

Borle K, Morris E, Inglis A, Austin J. 2018. Risk communication in genetic counseling: exploring uptake and perception of recurrence numbers, and their impact on patient outcomes. Clin Genet 94: 239-245. doi:10.1111/ cge. 13379

Costain G, Esplen MJ, Toner B, Hodgkinson KA, Bassett AS. 2014a. Evaluating genetic counseling for family members of individuals with schizophrenia in the molecular age. Schizophr Bull 40: 88-99. doi:10.1093/schbul/ sbs 124

Costain G, Esplen MJ, Toner B, Scherer SW, Meschino WS, Hodgkinson KA, Bassett AS. 2014b. Evaluating genetic counseling for individuals with schizophrenia in the molecular age. Schizophr Bull 40: 78-87. doi:10.1093/schbul/ sbs 138
Dazzi T, Gribble R, Wessely S, Fear NT. 2014. Does asking about suicide and related behaviours induce suicidal ideation? What is the evidence? Psychol Med 44: 3361-3363. doi:10.1017/S0033291714001299

DeLisi LE, Bertisch H. 2006. A preliminary comparison of the hopes of researchers, clinicians, and families for the future ethical use of genetic findings on schizophrenia. Am J Med Genet B Neuropsychiatr Genet 141B: 110-115. doi:10.1002/ajmg.b.30249

Eijzenga W, Aaronson NK, Hahn DEE, Sidharta GN, van der Kolk LE, Velthuizen ME, Ausems MGEM, Bleiker EMA. 2014. Effect of routine assessment of specific psychosocial problems on personalized communication, counselors' awareness, and distress levels in cancer genetic counseling practice: a randomized controlled trial. J Clin Oncol 32: 2998-3004. doi:10.1200/JCO.2014.55.4576

Erickson JA, Kuzmich L, Ormond KE, Gordon E, Christman MF, Cho MK, Levinson DF. 2014. Genetic testing of children for predisposition to mood disorders: anticipating the clinical issues. J Genet Couns 23: 566-577. doi:10 .1007/s10897-014-9710-y

Finn CT, Smoller JW. 2006. Genetic counseling in psychiatry. Harvard Rev Psych 14: 109-121.

First MB, Williams JBW, Karg RS, Spitzer RL. 2015. Structured Clinical Interview for DSM-5 Disorders, Clinical Trials Version (SCID-5-CT). American Psychiatric Association, Arlington, VA.

Gershon E, Alliey-Rodriguez N. 2013. New ethical issues for genetic counseling in common mental disorders. Am J Psych 170: 968-976.

Hippman C, Lohn Z, Ringrose A, Inglis A, Cheek J, Austin JC. 2013. 'Nothing is absolute in life': Understanding uncertainty in the context of psychiatric genetic counseling from the perspective of those with serious mental illness. J Genet Couns 22: 625-632. doi:10.1007/s10897013-9594-2

Hippman C, Ringrose A, Inglis A, Cheek J, Albert AYK, Remick R, Honer WG, Austin JC. 2016. A pilot randomized clinical trial evaluating the impact of genetic counseling for serious mental illnesses. J Clin Psychiatry 77: e190-e198. doi:10.4088/JCP.14m09710

Hodgkinson KA, Murphy J, O’Neill S, Brzustowicz L, Bassett AS. 2001 Genetic counselling for schizophrenia in the era of molecular genetics. Can J Psych 46: 123-130.

Hunter MJ, Hippman C, Honer WG, Austin JC. 2009. Genetic counseling for schizophrenia: a review of referrals to a provincial medical genetics program from 1968 to 2007. Am J Med Genet A 152: 147-152.

Inglis A, Koehn D, McGillivray B, Stewart SE, Austin J. 2015. Evaluating a unique, specialist psychiatric genetic counseling clinic: uptake and impact. Clin Genet 87: 218-224. doi:10.1111/cge.12415

Inglis A, Morris E, Austin J. 2017. Prenatal genetic counselling for psychiatric disorders. Prenat Diagn 37: 6-13. doi:10.1002/pd.4878

Kalb FM, Vincent V, Herzog T, Austin J. 2017. Genetic counseling for alcohol addiction: assessing perceptions and potential utility in individuals with lived experience and their family members. J Genet Couns 26: 963-970. doi:10.1007/s10897-017-0075-x 
J.C. Austin

Kay SR, Fiszbein A, Opler LA. 1987. The Positive and Negative Syndrome Scale (PANSS) for schizophrenia. Schizophr Bull 13: 261-276. doi:10.1093/schbul/13.2.261

Kumar P. 1968. Genetic counselling in family planning. Antiseptic 65: 831-834.

Leach E, Morris E, White HJ, Inglis A, Lehman A, Austin J 2016. How do physicians decide to refer their patients for psychiatric genetic counseling? A qualitative study of physicians' practice. J Genet Couns 25: 1235-1242. doi:10.1007/s10897-016-9961-x

Lorig K, Stewart A, Ritter P, Gonzalez V, Laurent D, Lynch J. 1996. Outcome measures for health education and other healthcare interventions. Sage, Thousand Oaks, CA.

Lyus VL. 2007. The importance of genetic counseling for individuals with schizophrenia and their relatives: potential clients' opinions and experiences. Am J Med Genet B 144B: 1014-1021. doi:10.1002/ajmg.b.30536

Maxwell EM. 2018. Family interview for genetic studies. Nimhgenetics.org [accessed July 31, 2019]. https://www .nimhgenetics.org/interviews/figs/FIGS\%201.0\% 20Manual\%20-\%20Aug\%201992.pdf.

McAllister M, Wood AM, Dunn G, Shiloh S, Todd C. 2011 The genetic counseling outcome scale: a new patient-reported outcome measure for clinical genetics services. Clin Genet 79: 413-424. doi:10.1111/j.1399-0004.2011 .01636.x

Meiser B, Mitchell PB, McGirr H, Van Herten M, Schofield PR. 2005. Implications of genetic risk information in families with a high density of bipolar disorder: an exploratory study. Soc Sci Med 60: 109-118. doi:10.1016/j .socscimed.2004.04.016

Meiser B, Kasparian NA, Mitchell PB, Strong K, Simpson JM, Tabassum L, Mireskandari S, Schofield PR. 2008. Attitudes to genetic testing in families with multiple cases of bipolar disorder. Genet Test 12: 233-243. doi:10.1089/ gte.2007.0100

Miller DT, Adam MP, Aradhya S, Biesecker LG, Brothman AR, Carter NP, Church DM, Crolla JA, Eichler EE, Epstein CJ, et al. 2010. Consensus statement: chromosomal microarray is a first-tier clinical diagnostic test for individuals with developmental disabilities or congenital anomalies. Am J Hum Genet 86: 749-764. doi:10.1016/j .ajhg.2010.04.006

Moldovan R, Pintea S, Austin J. 2017. The efficacy of genetic counseling for psychiatric disorders: a meta-analysis. $J \mathrm{Ge}$ net Couns 26: 1341-1347. doi:10.1007/s10897-017-0113-8
Moldovan R, McGhee K, Coviello DA, Hamang A, Inglis A, Ingvoldstad Malmgren C, Johansson-Soller M, Laurino M, Meiser B, Murphy L, et al. 2019. Psychiatric genetic counseling: a mapping exercise. Am J Med Genet B Neuropsychiatr Genet doi:10.1002/ajmg.b.32735

Morris E, Hippman C, Murray G, Michalak EE, Boyd JE, Livingston J, Inglis A, Carrion P, Austin J. 2018. Selfstigma in relatives of people with mental illness scale: development and validation. Br J Psychiatry 212: 169174. doi:10.1192/bjp.2017.23

Peay H, Austin J. 2011. How to talk with families about genetics and psychiatric illness. W.W. Norton, New York.

Quaid KA, Aschen SR, Smiley CL, Nurnberger JI Jr. 2001. Perceived genetic risks for bipolar disorder in a patient population: an exploratory study. J Genet Couns 10: 4151. doi:10.1023/A:1009403329873

Quinn V, Meiser B, Wilde A, Cousins Z, Barlow-Stewart K, Mitchell PB, Schofield PR. 2014. Preferences regarding targeted education and risk assessment in people with a family history of major depressive disorder. J Genet Couns 23: 785-795. doi:10.1007/s10897-013-9685-0

Resta R, Biesecker BB, Bennett RL, Blum S, Estabrooks Hahn S, Strecker MN, Williams JL. 2006. A new definition of genetic counseling: National Society of Genetic Counselors' Task Force report. J Genet Couns 15: 77-83. doi:10 .1007/s10897-005-9014-3

Reveley A. 1985. Genetic counseling for schizophrenia. $\mathrm{Br} J$ Psych 147: 107-112.

Schmitt A, Malchow B, Hasan A, Falkai P. 2014. The impact of environmental factors in severe psychiatric disorders. Front Neurosci 8: 19. doi:10.3389/fnins.2014.00019

Semaka A, Austin J. 2019. Patient perspectives on the process and outcomes of psychiatric genetic counseling: an "empowering encounter”. J Genet Couns 28: 856-868. doi:10 $.1002 /$ jgc4.1128

Slomp C, Morris E, Inglis A, Lehman A, Austin J. 2018. Patient outcomes of genetic counseling: assessing the impact of different approaches to family history collection. Clin Genet 93: 830-836.

Stancer HC, Wagener DK. 1984. Genetic counselling: its need in psychiatry and the directions it gives for future research. Can J Psych 29: 289-294.

Wilhelm K, Meiser B, Mitchell PB, Finch AW, Siegel JE, Parker G, Schofield PR. 2009. Issues concerning feedback about genetic testing and risk of depression. Br J Psychiatry 194: 404-410. doi:10.1192/bjp.bp.107.047514 


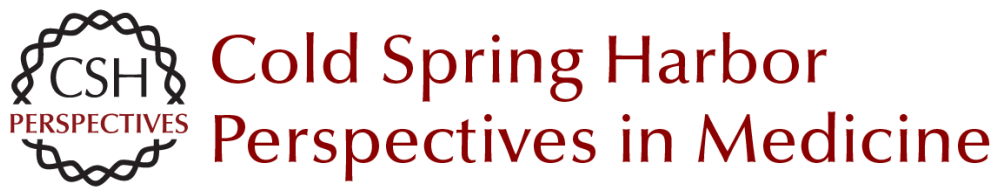

\section{Evidence-Based Genetic Counseling for Psychiatric Disorders: A Road Map}

Jehannine C. Austin

Cold Spring Harb Perspect Med 2020; doi: 10.1101/cshperspect.a036608 originally published online September 9, 2019

Subject Collection Genetic Counseling: Clinical Practice and Ethical Considerations

Genetic Risk Assessment in Psychiatry

Holly Landrum Peay

Birds of a Feather? Genetic Counseling, Genetic

Testing, and Humanism

Robert Resta

Bridging the Gap between Scientific Advancement and Real-World Application: Pediatric Genetic

Counseling for Common Syndromes and

Single-Gene Disorders

Julie A. McGlynn and Elinor Langfelder-Schwind

Genetic Counseling, Personalized Medicine, and

Precision Health

Erica Ramos

Tumor-Based Genetic Testing and Familial Cancer

Risk

Andrea Forman and Jilliane Sotelo

A Person-Centered Approach to Cardiovascular Genetic Testing

Julia Platt

Evidence-Based Genetic Counseling for

Psychiatric Disorders: A Road Map Jehannine C. Austin

Supporting Patient Autonomy and Informed

Decision-Making in Prenatal Genetic Testing

Katie Stoll and Judith Jackson
Impact of Emerging Technologies in Prenatal

Genetic Counseling

Blair Stevens

Genetic Counseling and Assisted Reproductive

Technologies

Debra Lilienthal and Michelle Cahr

Evolving Roles of Genetic Counselors in the

Clinical Laboratory

Megan T. Cho and Carrie Guy

Psychological Issues in Managing Families with Inherited Cardiovascular Diseases Jodie Ingles

Informed Consent in the Genomics Era Shannon Rego, Megan E. Grove, Mildred K. Cho, et al.

Predictive Genetic Counseling for

Neurodegenerative Diseases: Past, Present, and

Future Jill S. Goldman

Cancer Genetic Counseling--Current Practice and

Future Challenges Jaclyn Schienda and Jill Stopfer

Regulating Preimplantation Genetic Testing across the World: A Comparison of International

Policy and Ethical Perspectives

Margaret E.C. Ginoza and Rosario Isasi

For additional articles in this collection, see http://perspectivesinmedicine.cshlp.org/cgi/collection/ 